\title{
Long-Standing Course of Disease in a Patient with Muir-Torre Syndrome
}

\author{
Maliha Khan ${ }^{1}$ and Humaid 0 Al-Shamsi ${ }^{2 *}$ \\ ${ }^{1}$ Department of Leukemia, University of Texas \& MD Anderson Cancer Center, USA \\ ${ }^{2}$ Department of Medicine, University of Sharjah, United Arab Emirates
}

Submission: May 29, 2018; Published: June 11, 2018

*Corresponding author: Humaid O Al-Shamsi, Department of Medicine, University of Sharjah, Sharjah, United Arab Emirates, Fax: +97168824406;

Tel: +971506315388; Email: Humaid.Al-Shamsi@medportal.ca

\section{Introduction}

Muir-Torre Syndrome (MTS) is an autosomal dominant disorder characterized by skin neoplasms in association with a visceral malignancy [1]. Visceral malignancies most commonly seen with MTS include colorectal adenocarcinomas and genitourinary malignancies [2], while sebaceous adenomas, epitheliomas and carcinomas constitute the common dermatologic neoplastic conditions usually associated with MTS [2]. Due to its association with germline mutations in the DNA mismatch repair genes MLH1 and MLH2, which occur secondary to DNA microsatellite instability, MTS is considered as a small phenotypic subset of Lynch syndrome [3]. MTS is an exceedingly rare condition, with a high degree of variability in its penetration and expression [4]. Here, we describe a case of a 78-year old man with multiple visceral and dermatologic malignancies who had a prolonged and convoluted course of disease spanning over 40 years.

\section{Case Report}

A 78-year old male of German origin presented to our institution with a long-standing history of multiple cancers including colon cancer, acute myelogenous leukemia (AML), urothelial cancer, rectal cancer, and sebaceous adenoma dating back to 1968. A timeline of his malignancies is also included (Figure 1).

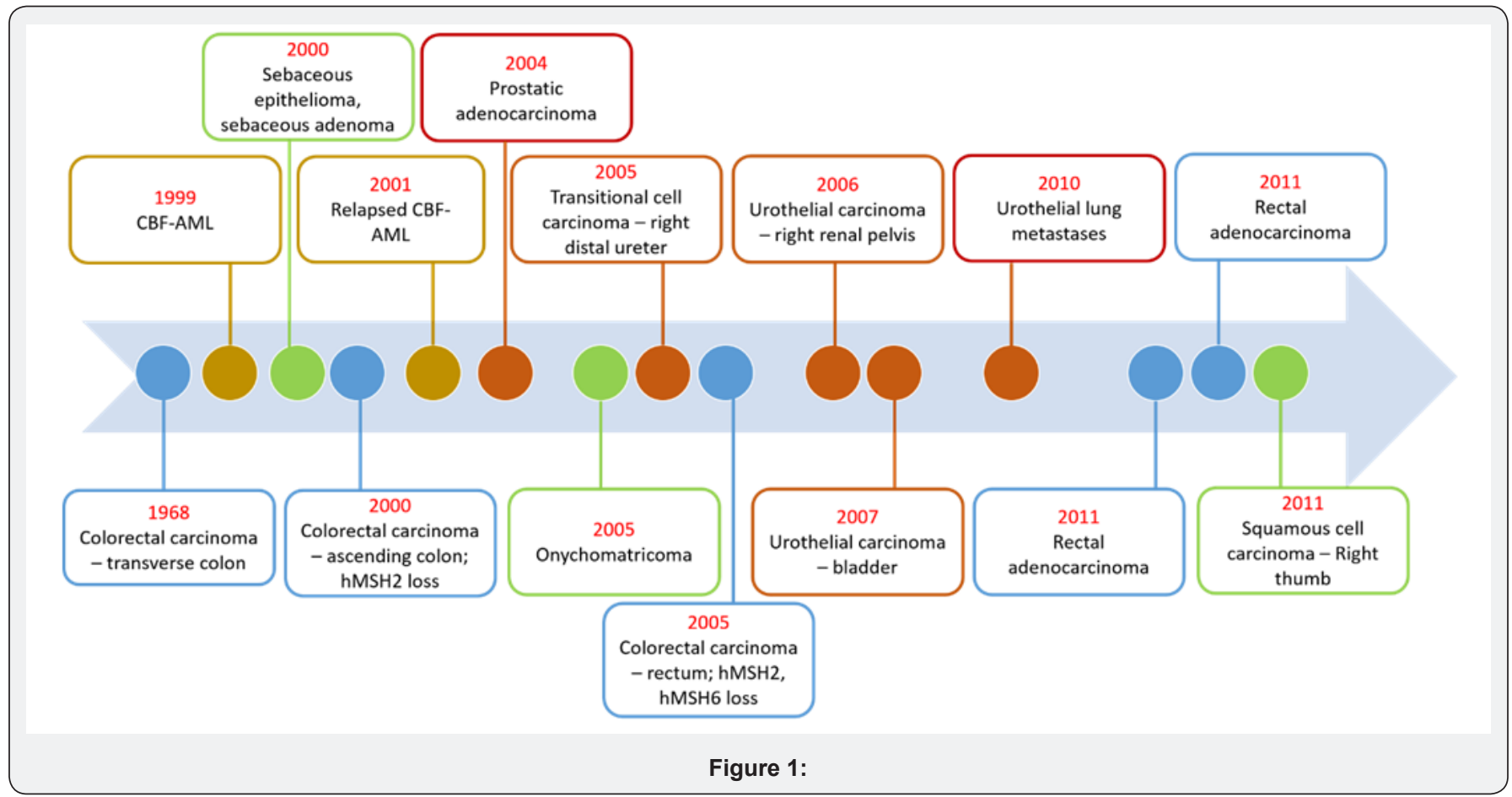




\section{Gastrointestinal neoplasms}

Patient was initially diagnosed with transverse colon cancer in 1968, for which he underwent transverse colectomy. He was then diagnosed with a second T3, N0 ascending colon adenocarcinoma in 2000, pathology of which revealed a mucinous adenocarcinoma with an allelic shift in 5 of 5 microsatellite markers and loss of nuclear expression ofhMSH-2 on immunohistochemistry (IHC) indicative of a MSI-high tumor. He underwent total colectomy. Later, in 2005, the patient was diagnosed with a rectal adenocarcinoma IHC of which showed tumor cells with positive nuclear staining for hMLH-1, but loss of hMSH-2 and hMSH-6expression. He was treated with definitive chemoradiation with concomitant capecitabine but in 2011 developed recurrent moderately differentiated adenocarcinoma of the rectum and received palliative radiation therapy.

\section{Genitourinary neoplasms}

Patient developed grade 2-3 non-invasive transitional cell carcinoma of the distal right ureter in 2005 and underwent multiple transurethral resections. His course was complicated by multiple other urothelial malignancies, including a grade 3 multifocal urothelial carcinoma involving renal pelvis and ureter that was managed with a right nephroureterectomy in 2006, a grade 2 urothelial bladder carcinoma in 2007 treated with Bacillus Calmette-Guérin (BCG) immunotherapy and a solitary lung metastasis in 2010, treated with radiation. Unusually, the patient was diagnosed with prostatic adenocarcinoma in 2004 which was managed with total prostatectomy and pelvic node dissection.

\section{Dermatology manifestations}

His dermatological history was significant for multiple lesions consistent with basal cell carcinoma and squamous cell carcinoma during adulthood. In 2000, the patient was diagnosed with a sebaceous epithelioma on right cheek and a sebaceous adenoma on right side of the neck. For these dermatologic conditions, the patient had undergone multiple Mohs surgeries. The patient also had a longstanding history of onychomatricoma, diagnosed on histopathology in 2005.

\section{AML}

In 1999, he presented with constitutional symptoms of fever and malaise and was diagnosed with core binding factor (CBF)-acute myeloid leukemia (AML) with inversion 16. He received induction chemotherapy with liposomal daunorubicin and cytarabine with thalidomide, achieved complete molecular remission, consolidation chemotherapy with low dose cytarabine for 5 cycles. In 2001, he relapsed with CBF-AML and received chemotherapy with FLAG (fludarabine + high-dose cytarabine + G-CSF) regimen and achieved second complete remission.

His family history was significant for an unknown CNS tumor in the patient's father. His sister had also been diagnosed with cervical cancer, and also additionally had skin lesions biopsied that were consistent with sebaceous neoplasms. His three children were all alive and healthy. The patient had been a lifelong non-smoker, a social drinker and had not reported any occupational exposures, including chemical or radiation exposures.

\section{Discussion}

Hereditary non-polyposis colorectal cancer (HNPCC), also called Lynch syndrome, is associated with microsatellite instability leading to genetic defects in DNA mismatch repair genes [1]. These mismatch repair genes are key players in recognizing nucleotide mismatches, deletions and insertions that occur during DNA replication, correcting such mutations and preventing their propagation in progeny cells [5]. Six DNA mismatch repair genes have been implicated as the cause of the neoplasms seen in HNPCC. These include the genes MSH2, MLH1, MSH3, MSH6, PMS1 and PMS2. Mutations in these mismatch repair genes have been shown to predispose patients to developing neoplasms of the colorectal region, as well as those of other viscera $[1,2]$.

Muir-Torre syndrome, first described in 1967, is characterized by the presence of dermatologic neoplasms of sebaceous origin, in association with an internal malignancy [6]. MTS is usually diagnosed later in life, with a median age of 55 years, and has a 3:2 male: female distribution [2]. MSH2, found on chromosome 2(p22-p21), was the first mutated gene observed in patients with MTS [4]. Of the six genes implicated in Lynch syndrome, gene mutations in the MSH2 gene have most commonly been described as associated with MTS, followed by the MSH1 gene $[4,7]$. This is in contrast to HNPCC, where MSH1 is the defect observed most often [8]. Recently, MSH6 mutations have additionally been described in patients fitting diagnostic criteria for MTS, further increasing the genotypic variance seen in this syndrome [9].

Our patient, who was documented to have a defect in the MSH2 gene, presented with a long-standing history spanning over 40 years of multiple cutaneous and visceral malignancies, with a unique and long-standing course of disease. The types of malignancies seen in Muir-Torre syndrome [4] are either cutaneous or visceral malignancies, with colorectal neoplasms as the most common visceral manifestation. These visceral malignancies often run concurrent to each other, and may precede or follow the dermatologic neoplasms [4]. It is interesting to note, however, that patients with MTS often present with less severe manifestations of both their visceral and dermatologic malignancies, in contrast to patients presenting with such neoplasms in the absence of a syndromic involvement [5].

Our patient also initially presented with a colorectal malignancy in 1968 [10]. However, while most cases occur proximal to the splenic flexure [11], his disease course 
progressively involved the length of his colon and rectum. When ultimately the patient decided not to pursue chemotherapy further, he was still being managed for a recurrence of his rectal carcinoma. Our patient also received oral capecitabine for his advanced colorectal carcinoma in concurrence with radiotherapy. Capecitabine is a fluoropyrimidine that is metabolized to 5 - FU, and has been shown to have equal efficacy to 5 -FU in metastatic or advanced colorectal cancers, with a better side effect profile [12].

Sebaceous adenomas, carcinomas and keratocanthomas are most strongly associated with MTS [1]. These dermatologic neoplasms may occur before, in conjunction with, or precede an internal malignancy, but are most commonly seen after a visceral malignancy. This was also the case in this patient. Although our patient was diagnosed with multiple squamous cell and basal cell carcinomas in earlier life, it was quite later in his disease course that he was diagnosed with a sebaceous malignancy, with a time span of 32 years between his initial visceral malignancy and his sebaceous neoplasm. He also had a documented onychomatricoma, an extremely rare benign subungual tumor diagnosed on the basis of histopathological features [13,14]. In our extensive literature review, we were unable to find mention of an onychomatricoma in a patient with Muir-Torre syndrome.

The patient also exhibited the second most common visceral malignancy seen in MTS i.e. genitourinary malignancies. His malignancy extended to the prostate, bladder, ureter and renal pelvis. Prior to the patient's death, he also had an undiagnosed psoas mass. Despite management of all his urothelial malignancies, the patient presented later in the course of his disease with a pulmonary nodule which was determined on biopsy to be of urothelial origin. Our patient also received Bacillus Calmette-Guérin (BCG) immunotherapy for his grade 2 urothelial malignancy. BCG has been documented to reduce the risk of progression following transurethral resection in patients with bladder cancer at stage 2 or worse [15].

Our patient's family history was significant for a sister with cervical cancer and cutaneous lesions including sebaceous gland carcinomas, consistent with the autosomal dominant nature of his disease. We underscored to him the need for his three children to go surveillance for the development of both cutaneous and visceral malignancies, especially colorectal cancers. The American Cancer Society recommends colonoscopy at 1-2 year intervals with genetic testing for patients with a high risk of HNPCC [16].

Muir-Torre syndrome can result in a wide variety of clinicopathlogical presentations, and usually follow a longstanding course of disease, as seen in our patient with a history going back over four decades. The presence of characteristic cutaneous malignancies, in association with a visceral malignancy may be clues to MTS, and Lynch syndrome in general. The ability to correlate the multitude of malignant neoplasms can lead to an earlier diagnosis and better management of such patients.

\section{References}

1. Bhaijee F, Brown AS (2014) Muir-Torre Syndrome. Archives of Pathology \& Laboratory Medicine 138(12): 1685-1689.

2. Schwartz RA, Torre DP (1995) The Muir-Torre syndrome: a 25-year retrospect. J Am Acad Dermatol 33(1): 90-104.

3. Yozu M, Symmans P, Dray M, Griffin J, Han C, et al. (2013) Muir-Torre syndrome-associated pleomorphic liposarcoma arising in a previous radiation field. Virchows Arch 462(3): 355-360.

4. Akhtar S, Oza KK, Khan SA, Wright J (1999) Muir-Torre syndrome: case report of a patient with concurrent jejunal and ureteral cancer and a review of the literature. J Am Acad Dermatol 41(5 Pt 1): 681-686.

5. Abbas O, Mahalingam M (2009) Cutaneous sebaceous neoplasms as markers of Muir-Torre syndrome: a diagnostic algorithm. J Cutan Pathol 36(6): 613-619.

6. Muir EG, Bell AJ, Barlow KA (1967) Multiple primary carcinomata of the colon, duodenum, and larynx associated with kerato-acanthomata of the face. Br J Surg 54(3): 191-195.

7. Ponti G, Losi L, Pedroni M, Cordisco EL, Di Gregorio C, et al. (2006) Value of MLH1 and MSH2 mutations in the appearance of Muir-Torre syndrome phenotype in HNPCC patients presenting sebaceous gland tumors or keratoacanthomas. J Invest Dermatol 126(10): 2302-2307.

8. Mangold E, Pagenstecher C, Leister M, Mathiak M, Rutten A, et al. (2004) A genotype-phenotype correlation in HNPCC: strong predominance of msh2 mutations in 41 patients with Muir-Torre syndrome. J Med Genet 41(7): 567-572.

9. Murphy H, Armstrong R, Cairns D, Greenhalgh K (2008) Muir-Torre syndrome: expanding the genotype and phenotype-a further family with a MSH6 mutation. Familial cancer 7(3): 255-257.

10. Ponti G, de Leon MP (2005) Muir-torre syndrome. The lancet oncology 6(12): 980-987.

11. Navi D, Wadhera A, Fung MA, Fazel N (2006) Muir-Torre syndrome. Dermatology online journal 12(5): 4.

12. Van Cutsem E, Twelves C, Cassidy J, Allman D, Bajetta E, et al. (2001) Oral capecitabine compared with intravenous fluorouracil plus leucovorin in patients with metastatic colorectal cancer: results of a large phase III study. J Clin Oncol 19(21): 4097-4106.

13. Lesort C, Debarbieux S, Duru G, Dalle S, Poulhalon N, et al. (2015) Dermoscopic Features of Onychomatricoma: A Study of 34 Cases. Dermatology 231(2): 177-183.

14. Perrin C, Baran R, Pisani A, Ortonne JP, Michiels JF (2002) The onychomatricoma: additional histologic criteria and immunohistochemical study. Am J Dermatopathol 24(3): 199-203.

15. Sylvester RJ, van der PMA, Lamm DL (2002) Intravesical bacillus Calmette-Guerin reduces the risk of progression in patients with superficial bladder cancer: a meta-analysis of the published results of randomized clinical trials. J Urol 168(5): 1964-1970.

16. Levin B, Lieberman DA, McFarland B, Smith RA, Brooks D, et al. (2008) Screening and surveillance for the early detection of colorectal cancer and adenomatous polyps, 2008: a joint guideline from the American Cancer Society, the Us Multi-Society Task Force On Colorectal Cancer, and the American College Of Radiology. CA Cancer J Clin 58(3): 130160 . 


\section{Your next submission with Juniper Publishers will reach you the below assets}

- Quality Editorial service

- Swift Peer Review

- Reprints availability

- E-prints Service

- Manuscript Podcast for convenient understanding

- Global attainment for your research

- Manuscript accessibility in different formats ( Pdf, E-pub, Full Text, Audio)

- Unceasing customer service

Track the below URL for one-step submission https://juniperpublishers.com/online-submission.php 